Synthesis

\title{
Biological Diversity and Resilience: Lessons from the Recovery of Cichlid Species in Lake Victoria
}

\author{
${\underline{\text { Alex } O . \text { Awiti }^{1}}}^{1}$
}

\begin{abstract}
A fundamental feature of the Anthropocene is the inexorable erosion of the self-repairing capacity or adaptive renewal of natural systems because of natural perturbation, exploitation, or management failure. The concept of resilience offers a systematic framework for understanding the dynamics and variables that govern response dynamics of ecosystems. Resilience of haplochromine cichlids is assessed using limnological and biodiversity changes in Lake Victoria, the world's second largest freshwater lake, over the last five decades. The review explores the resurgence of the haplochromine cichlids using Holling's adaptive renewal cycle and attempts to illustrate how resilience-based management approaches might learn from an inadvertent management experiment. The introduction in the 1980s of the Nile perch (Lates niloticus), a fecund and voracious predator of the endemic phytoplankton feeding haplochromine cichlids, anthropogenic eutrophication, and deep water hypoxia have combined in a synergistic way to increase the vulnerability of the lake ecosystem to perturbations that were hitherto absorbed. However, the upsurge in commercial Nile perch fishing appears to be enabling the resurgence of the haplochromine cichlids. The resurgence of haplochromine cichlids is characterized by phenotypic plasticity, ecological and life history traits and demonstrates the critical role of response diversity in the maintenance of systems resilience. Resilience of the haplochromine cichlids resides in the requisite functional response diversity and habitat diversity that provide the resources for renewal and regeneration. This paper concludes that management of Nile perch fisheries and control of nutrient loading into Lake Victoria could halt or reverse eutrophication, hence offer the best promise for a diverse, productive, and resilient social-ecological system.
\end{abstract}

Key Words: eutrophication; Lake Victoria; Nile perch; recovery of haplochromine cichlids; resilience; response diversity

\section{INTRODUCTION}

We live today in what has been called the Anthropocene (Crutzen 2002). This is an epoch in which mankind has emerged as a globally dominant force capable of reshaping ecological and biogeochemical processes from local to global scales. The conundrum of ecosystem management and policy in the Anthropocene is not a capacity to predict the future and forestall change or disturbance, but a capacity to create or enable adaptive renewal through memory, reorganization, transformation, and continuous learning. Moreover, our civilization is confronted with more variable environments and even greater uncertainty regarding how social and ecological systems will respond to further anthropogenic transformations, including human induced climate change.

A fundamental footprint of the Anthropocene is the inexorable erosion of the self-repairing capacity or adaptive renewal of natural systems owing to natural perturbation, exploitation, or management failure. What is needed, therefore, in the Anthropocene, is a new management paradigm; a paradigm that encourages prospective or experimental management thus fostering adaptive renewal in dynamic and uncertain social-ecological systems. Old paradigms have assumed equilibrium, the notion that populations or resources fluctuate around some trend or stable average (Scheffer and Carpenter 2003) that is governed by command-and- 
control for stable optimal production (Holling and Meffe 1996) and maintenance of a predictable world (Holling 1973). The command-and-control paradigm assumes that problems are well bounded, that systems are in line with respect to cause and effect and hence would return inevitably to a desirable stable equilibrium whenever human stressors are discontinued. The command-and-control paradigm of the Anthropocene has invariably led to loss of systems resilience through the collapse of the natural resource base, socioeconomic strife, and loss of biological diversity (Holling and Meffe 1996).

The existential imperative of the Anthropocene is an approach to managing natural systems that is adaptive and capable of dealing with change, both natural and anthropogenic, uncertainty, and complexity. What is needed is a resilience-based approach to human stewardship of fragile and rapidly changing natural resource base. The concept of resilience first appeared in ecological lexicon with C. S. Holling's review paper of 1973. Resilience thinking now permeates discussions about global social-ecological concerns and especially adaptation to climate change. A fundamental property of resilience concerns the capacity for self-repair or adaptive renewal and reorganization of social-ecological systems following perturbation. Given the magnitude of anthropogenic transformation, the role of biodiversity as it relates to the biological resources for adaptive renewal and reorganization of ecological systems is critical. Elmqvist et al. (2003) have argued that diversity of responses to environmental change among species contributing to the same ecosystem function is critical to resilience. The diversity of persisting organisms, structures processes, and patterns, referred to as biological legacies, are critical threads of continuity and can drive pathways of reorganization and selfrenewal (Franklin and MacMahon 2000, Pharo and Lindenmayer 2009).

The recent history of Lake Victoria fisheries exemplifies a direction and magnitude of change that is disconcerting. A fishery that once drew on hundreds of species, mostly endemic, now depends on just three: Rastrineobola argentea, a native pelagic cyprinoid fish commonly known as omena or dagaa; the introduced Nile perch (Lates niloticus); and the Nile tilapia (Oreochromis niloticus). In Lake Victoria, as elsewhere, societal welfare is coupled with concern for species conservation and ecosystem integrity. Coupled social-ecological systems provide a conceptual framework for understanding systems not as deterministic and predictable, but as complex, integrated, with feedbacks and emergent properties among ecological and social components at multiple spatial and temporal scales.

The changes in Lake Victoria are examined within the framework of a coupled social-ecological system. For instance, the components such as the resource system, e.g., the lake, land; resource units, i.e., fish, phytoplankton, vegetation, soil; users, i.e., managers, fishers, and farmers, who exploit and regulate the resource units are relatively distinct but interact to produce outcomes that in turn produce reciprocal effects and emergent properties at the ecological and social levels. Understanding reciprocal effects and emergent properties is essential to understanding resilience mechanisms and developing effective policies for socialecological sustainability of an ecosystem.

The paper reviews literature on the recent ecological history of Lake Victoria fisheries to examine the relationship between biodiversity of haplochromine cichlids and their resurgence. This paper focuses on the role of biodiversity in the resurgence of haplochromine cichlids in Lake Victoria. In this respect, the functional-group and functionalresponse value of biological diversity is examined. More importantly, the synthesis attempts to examine the dynamics of the Lake Victoria ecosystem using the framework of Holling's adaptive renewal cycle.

\section{RESILIENCE AND BIODIVERSITY OF ECOSYSTEMS}

\section{The concept resilience}

Sustainability and its derivative sustainable development (WCED 1987) were hailed as a robust response to the scale of anthropogenic transformation. The goal of sustainable development is to reduce inputs in globalized economic growth model, i.e., energy, land water, and vegetation, while at the same time minimizing outputs and consumption, i.e., pollution, biodiversity loss, and land degradation. Consider French bean farming for export in Kenya. Conventional sustainability thinking would argue that it is possible to enhance water use efficiency, reduce carbon emissions by using less fertilizer, less packaging, and installing 
more energy efficient cold rooms. However, reduction in the production of local food crops when local farmers switch to lucrative export oriented farming, the collapse of local food markets, and dependence on European markets has increased the vulnerability of local household income and caused a reduction of farm-level agrobiodiversity. The fundamental limitation of the concept of sustainable development is that it espouses a more utopian desire for greater efficiency rather than a coherent set of social and ecological outcomes that could enhance overall systems performance. Greater efficiency cannot resolve the real constraints imposed by the finite nature of resources derived from the physical world. We suggest that resilience thinking is a critical yet missing dimension to the sustainability discourse.

The term resilience is now increasingly used in discussions about local and global development as a framework for understanding social and ecological change in the wake of unprecedented anthropogenic and natural transformations. Holling (1973:17) defined resilience as the "measure of a system's ability to absorb changes of state variables, driving variables and parameters, and still persist." Holling noted that persistence was also a measure of stability, or the magnitude of perturbation a system can withstand before it shifts to another state or domain of attraction. John Dewey (1859-1952), the renowned 20th century American educational philosopher, described persistence as dynamic selfrenewal and reorganization. In humanistic psychology, resilient individuals seem not only to cope well with stressors but also experience such challenges as learning and self-renewal opportunities.

Folke (2006) argued that social-ecological resilience is about new opportunities arising from disturbance through system renewal, selforganization, and emergence of new trajectories. Self-organizing systems allow adaptation, confer systems flexibility buffer disturbance, and create novelty (Holling and Gunderson 2002) through differentiation, selection, and amplification. Resilience demonstrates how without contradiction, transformation and persistence interact synergistically, enabling species, populations, communities, ecosystems, and institutions to assimilate change, innovate, and create novelty, while at the same time maintaining identity through characteristic structures, processes, and functions. Change and persistence, through cycles of adaptive renewal and reorganization have emerged as the defining characteristics of the concept of resilience. Resilience is defined here as the capacity of linked social-ecological systems (Adger et al. 2005) to absorb disturbance and reorganize through local cycles of adaptive renewal at hierarchical scales (Holling and Gunderson 2002) to retain identity, basic function, structure, and feedbacks (Walker et al. 2004).

A key property of ecosystems is the existence of thresholds and multiple stable states and hence probability that a system in one stability domain will flip between or among stability domains (Scheffer et al. 2001). Such regime shifts may be triggered by habitat fragmentation, loss of species, nutrient inputs, or introduction of exotic species. Switches from one state to another are mediated by responses that trigger changes in variables, fast and slow, through thresholds, transitions, and feedbacks. Owing to the hysteresis of their response, ecosystems typically lack early warning signifiers for catastrophic regime shifts. Policy and management often focus on syndromes rather than the causal factors or events that undermine overall systems resilience. For example, human settlement and land use change in the Lake Victoria basin starting in the 1930s increased nutrient loading hence escalated vulnerability of the lake to eutrophication. The irruption of the Nile perch in the 1980s decimated the haplochromine cichlids, and thus accelerated algal production, exacerbated eutrophication, caused a loss of transparency and deep water hypoxia, and more cichlid die-offs.

Prior to crossing a threshold, key ecosystem variables are predicted to exhibit increased variability. Carpenter and Brock (2006) demonstrated that changes in variance around simple time series models could be used to detect the onset of regime shift in complex systems. Holling (1973) argued that resilience is the property of a system and persistence or probability of regime shift is the result. Intuitively, results or outcomes are reliable measures of a property. Resilience is related to the characteristics of a system that restrain variability of state or control variables from passing the threshold and transitioning to an alternative regime. However, resilience is also about transformation and renewal. Resilience can therefore be evaluated with respect to three attributes, namely: (1) the magnitude of disturbance or variability that a system can absorb and still retain the same range of state, driving variables, or structure and function; (2) the degree to which the system is capable of renewal or 
reorganization following perturbation or collapse; (3) the ability to build and increase adaptive capacity through endogenous experimentation, learning, and novelty.

\section{Biodiversity and resilience}

The intense global focus on the consequence of biodiversity loss on the supply of ecosystem services to human societies (MA 2005) has precipitated review and analysis of the relationship between biodiversity and ecological resilience. Ecological resilience refers to the capacity to absorb disturbance and reorganize while undergoing transformation so as to retain the same range of driving variables, structure, function, and feedbacks. Recent advances in resilience research are exploring how various features of biological diversity influence resilience, including diversity within species and the diversity of functional groups. For instance, Walker (1992) developed a passenger driver analogy to demonstrate the relationship between biodiversity and resilience, suggesting that species in the driver functional group are keystone species that determine the future of an ecosystem. Biological diversity therefore appears to enhance ecosystem resilience of desirable ecosystem states in the face of change (Peterson et al. 1998, Elmqvist et al. 2003).

The role of biodiversity in conferring adaptive capacity through renewal and reorganization is key to understanding the relationship between biodiversity and ecosystem resilience. Gunderson (2000) has argued that resilience is maintained by keystone structuring processes across spatial and temporal scales, sources of renewal and reformation, and functional biodiversity. Elmqvist et al. (2003) concluded that response diversity provides adaptive capacity and contributes resilience of desired ecosystem states. For example, Nystrom et al. (2000) demonstrated that a combination of increased nutrient loading and overfishing eroded responses diversity thus leading to an undesirable algae-dominated state in Caribbean reefs. The biological resources for adaptive renewal and reorganization following perturbation or collapse, i.e., functional response diversity, biological legacies, mobile links, and ecological memory (Franklin and MacMahon 2000, Elmqvist et al. 2003, Lundberg and Moberg, 2003, Folke et al. 2004) are therefore critical to system resilience.
Undesirable regime shifts in ecosystems are increasingly common as a consequence of actions that erode biological diversity. This section examines the relationship between biodiversity and ecosystem resilience in the context of the recent resurgence of the haplochromine cichlids in relation to functional-group and functional-response diversity.

\section{Biological diversity and dynamics of haplochromine cichlid resilience}

Lake Victoria is best known for its large flock of endemic haplochromines, until recently circa 500 species, arising in the last 15,000 years, representing one of the most rapid radiations of vertebrates known (Kaufman 1992). Lake Victoria has undergone profound ecological transformations in the last five decades. These include changes in phytoplankton composition and productivity (Hecky et al. 1994, Verschuren et al. 2002), the emergence of blue-green algae as the dominant species of planktonic algae, deep water anoxia (Hecky et al. 1994), and more importantly, the introduction in 1962-1963 and subsequent irruption in the 1980s of the Nile perch, (Lates nilotica) and the near extirpation of circa $65 \%$ of species of endemic haplochromine cichlids (Ogutu-Ohwayo 1990, Goldschmidt et al. 1993).

The diversity of functional groups in a dynamic lake ecosystem undergoing change, the diversity within species and populations, and the diversity of species in functional groups are critical for resilience and recovery of the lake fisheries. This section examines the resurgence of haplochromine cichlids in the context of functional-group diversity and functional-response diversity.

\section{a) Functional-group diversity}

Functional groups in the Lake Victoria ecosystem relate closely to trophic groups and include; piscivores, detritivores, phytoplanktivores, insectivores, and zooplanktivores. The introduction of the Nile perch, an apex voracious piscivore, is largely responsible for the near decimation of the detritivorous and phytoplanktivores haplochromine cichlids (Ogutu-Ohwayo 1990). Loss of detritivorous haplochromines is likely to have accelerated an algal production, exacerbating eutrophication, loss of transparency, and deep water hypoxia (Goldschmidt et al. 1993). Loss of water clarity 
hampers reproductive isolation thus destroying both the mechanisms of diversification and the maintenance of haplochromine diversity (Seehausen et al. 1997).

Moreover, Verschuren et al. (2002) have suggested that deoxygenation of deep water hypoxia could eliminate critical haplochromine refugia, exacerbating the vulnerability of haplochromine cichlids to Nile perch predation. Haplochromine cichlids may have faced the choice of death by asphyxia in the deep anoxic water or predation by the Nile perch in the oxygen-rich shallow waters (Kaufman 1992). The exotic Nile tilapia is associated with negative effects on the haplochromine cichlid biodiversity such as hybridization, overcrowding, competition for food, and possibly the introduction of parasites and diseases (Bruton 1990, Ogutu-Ohwayo 1990).

The introduction of the Nile tilapia and subsequent irruption of the Nile perch in the 1980s has caused significant shifts in the trophic structure resulting in the following major changes in the food web in Lake Victoria (Witte et al. 1992, Goldschmidt et al. 1993):

1. More than 100 species of haplochromine piscivores vanished, replaced by Nile perch;

2. The exotic Nile tilapia replaced the indigenous Oreochromis esculentus and $O$. variabilis;

3. Rastrineobola argentea replaced over 20 species of zooplanktivorous haplochromine cichlids;

4. Freshwater prawn (Caridina nilotica) replaced circa 13 species of the detritivorous haplochromine cichlids. $C$. nilotica is an important food source for the major commercial fish species of Lake Victoria (Budeba and Cowx 2007).

\section{b) Functional-response diversity}

After a dramatic irruption between 1980 and 1990, the Nile perch is in decline, largely because of overfishing. Witte et al. (1992) reported almost no haplochromines from a trawl survey in the Gulf of Mwanza in 1987 and 1988. Conversely, in a trawl survey conducted in the Gulf of Mwanza in 1997, the Nile perch biomass declined to $76 \%$ while that of haplochromine cichlids increased to $21 \%$ (Witte et al. 2000). However, the haplochromine cichlids are returning to a dramatically altered environment. The patterns of haplochromine cichlid resurgence in an altered ecosystem are examined in the context of response diversity (Elmqvist et al. 2003) to understand how differential response of haplochromine cichlids is critical to their resurgence.

The resurgence of Haplochromis (Yssichromis) pyrrhocephalus has been reported in the Mwanza Gulf of Lake Victoria (Witte et al. 2000, Katunzi et al. 2003). The recovery of $H$. (Y.) pyrrhocephalus presents exemplary evidence of functionalresponse diversity to: (1) high turbidity and poor visibility; (2) deep water hypoxia; and (3) change in diet. More importantly, the following functionaldiversity responses may explain the resurgence of $H$. (Y.) pyrrhocephalus: (1) the retina of $H$. (Y.) pyrrhocephalus consists of large double cones and has been interpreted as an adaptation to decreased transparency, hence enabling better visual observation of prey, predator, mate choice, and picking up of eggs by mouth brooding females (Seehausen et al. 1997, Witte et al. 2000); (2) gill surface area of the resurging $H$. (Y.) pyrrhocephalus is considerably larger than the pre-Nile perch specimen, a likely response or adaptation to hypoxia; and (3) the difficulty in spotting small prey owing to decline in water clarity has caused a dietary shift in the recovering $H$. (Y.) pyrrhocephalus. Diet analysis of the recovering $H$. (Y.) pyrrhocephalus indicates they eat larger prey comprising shrimps, molluscs, and fish more frequently (Katunzi et al. 2003) than before the Nile perch irruption. Similarly, the increase in fecundity observed in $H$. (Y.) pyrrhocephalus between 1983 and 1988 (Wanink 1991) may have been a response to increased predation pressure.

Haplochromine cichlids have reappeared in wetlands dominated by papyrus and rocky areas. These habitats provide both structural and low oxygen refugia and serve as barriers to dispersal of Nile perch (Chapman et al. 1995). Habitat diversity, i.e., rock outcrops and papyrus swamps, serves as important sources of renewal and ensures haplochromine cichlids are recruited back into the lake. We argue that the wetlands and rocky outcrops are critical biological legacies and contribute significantly to the restoration of compositional and functional biodiversity of the post-Nile perch regime ecosystem of Lake Victoria. The resilience of the haplochromine cichlid fisheries appears to be 
determined by the genetic diversity, functional and response diversity, and ecosystem diversity (beta diversity) across the range of habitats in Lake Victoria.

\section{TOWARD RESILIENCE-BASED ECOSYSTEMS MANAGEMENT}

Conventional ecosystem management has focused on maintaining pristine environments, often targeting keystone species and habitats based on a steady-state resource paradigm where humans are external to the managed system. The steady-state resource paradigm of ecosystem management assumes infinite flows of energy, materials, and biotic components, and that nature would reset, without feedback, to a single equilibrium or stable state upon cessation of disturbance. Moreover, conventional ecosystem management is encumbered by its focus on the pristine ecosystem state as a benchmark for policy formulation, conservation planning, and management response. Benchmarks are typically defined from a neontological perspective that ignores past environmental fluctuations and fails to anticipate future fluctuations.

Managed and unmanaged ecosystems are characterized by pulses of unanticipated shifts in dynamics in response to internal or external perturbations. In a dynamic environment, change is governed by slow or fast variables and complex feedback. Predictability is limited and there is always a high likelihood that existing management policy and practices are soon rendered invalid. This is especially true for coupled social-ecological systems such as Lake Victoria, which are characterized by cycles of accumulation, perturbation, readjustment, or collapse, and periods of reorganization. This paper argues that conventional ecosystem management is not sufficiently robust in the context of uncertainties, nonlinear dynamics, and complex feedback.

The goal of ecosystem management, therefore, must not be the maintenance of resource stocks in pristine condition, but rather to manage interactions and flows among functional biological diversity assemblages including feedbacks and emergent properties to enable transformation and persistence through reorganization and adaptive learning. The capacity of social-ecological systems to absorb perturbation, to transform, adapt, and reorganize while retaining the same structures, functions, and feedback is core to the concept and practice of resilience-based management.

The adaptive renewal cycle (Holling 1986, Holling and Gunderson 2002) provides an intuitive conceptual and management framework upon which to explore resilience-based ecosystem management for Lake Victoria. The adaptive renewal cycle can be decomposed into four phases. The first two phases, exploitation and conservation, referred to here as the frontloop, describe the conventional steady-state management (see Table $1)$. The frontloop depicts a typical succession sequence, from primordial constituents during exploitation, culminating in a mature complex climax community in the conservation phase. The next two phases of the adaptive renewal cycle, release and renewal, referred to here as the backloop, embody the principles of resilience-based ecosystem management, focusing on transformation, feedback, and reorganization (Table 1). The release, or creative destruction, and the reorganization phases have been largely ignored (Folke 2006) by conventional, i.e., steady state, management approaches that assume constancy of relationships, often with respect to management of a single species for maximum sustained yield. This section examines the dynamics of haplochromine cichlids using Holling's adaptive renewal cycle and attempts to draw lessons for resilience-based management approaches.

\section{Growth and conservation phase: frontloop}

The period of rapid accumulation of haplochromine cichlid biomass in Lake Victoria can be characterized as follows:

1. Rapid evolutionary radiation and phenotypic diversity;

2. Early human settlement and cultivation triggered low inflows of nutrients, mainly from soil erosion, into the lake thus increasing levels of primary productivity to enable the haplochromine cichlid boom;

3. Low levels of predation, low fishing effort, and high primary productivity supported large stocks of detritivorous haplochromine cichlids (Kaufman 1992); 
Table 1. Contrast between steady-state management and resilience-based ecosystems management.

\begin{tabular}{|c|c|}
\hline Steady-State paradigm & Resilience-based paradigm \\
\hline Manage benchmark state: pristine condition & Manage pathways of transformation or change \\
\hline $\begin{array}{l}\text { Manage for keystone species or habitat with humans } \\
\text { excluded explicitly }\end{array}$ & $\begin{array}{l}\text { Manage for coupled social-ecological outcomes with humans } \\
\text { included explicitly }\end{array}$ \\
\hline $\begin{array}{l}\text { Manage to reduce system variability and forestall } \\
\text { disturbance }\end{array}$ & Manage to cultivate system diversity and variability \\
\hline $\begin{array}{l}\text { Manage to optimize for single invariable outcome, with } \\
\text { single equilibrium or steady state }\end{array}$ & $\begin{array}{l}\text { Manage for a dynamic changing quantity, sustain persistence, } \\
\text { and transformation, with alternative stable states }\end{array}$ \\
\hline Manage for maximum sustained yield & $\begin{array}{l}\text { Management anticipates a range of possible options to cope } \\
\text { with internal or external perturbations and feedbacks }\end{array}$ \\
\hline Management actions that delay Release (frontloop) & Management actions that nurture Renewal (backloop) \\
\hline $\begin{array}{l}\text { Implement landscape level management, including } \\
\text { wetlands, forests, and lowland urban areas to reduce } \\
\text { eutrophication from nutrient run-off and urban effluence }\end{array}$ & $\begin{array}{l}\text { Maintaining structural diversity by protecting of critical } \\
\text { habitats such as wetlands and rocky habitats, which serve as } \\
\text { refugia and sites for breeding }\end{array}$ \\
\hline $\begin{array}{l}\text { Develop general ecosystems model of Lake Victoria that } \\
\text { includes the physical, chemical, biological, and } \\
\text { anthropogenic factors to understand and predict lake } \\
\text { productivity. }\end{array}$ & $\begin{array}{l}\text { Apply appropriate levels of fishing efforts on selected size } \\
\text { classes, such as the slot size described above, and target } \\
\text { species will contribute to maintenance and, potentially, } \\
\text { enhancement of biodiversity. }\end{array}$ \\
\hline $\begin{array}{l}\text { Quantify interactions among food-web structures, water } \\
\text { quality, and life-history characteristics of fishes to } \\
\text { understand the relationship between productivity of } \\
\text { haplochromine cichlids, Nile perch predation and the } \\
\text { causes of eutrophication, and anoxia in Lake Victoria. }\end{array}$ & $\begin{array}{l}\text { Identify and reduce anthropogenic nutrient inputs through } \\
\text { reforestation of upland catchment areas as well as reduction of } \\
\text { materials and contaminants in run-off. }\end{array}$ \\
\hline
\end{tabular}

4. Haplochromine cichlids composed $80 \%$ of fish biomass, and Nile perch less than $2 \%$;

5. The haplochromine cichlid boom provided sufficient grazing pressure on the phytoplankton and thus maintained high concentrations of deep water oxygen as well as sufficient illumination.

This resilience of the haplochromine cichlids in the conservation phase may have been related to the high proportion of haplochromine cichlids and the tight nutrient cycles they provided, thus enabling the vertical movement of nutrients and biomass in the course of their vertical and horizontal migrations (Kaufman 1992, Witte et al. 1992). This biological mixing could have been critical in lake dynamics to the extent that retarded the accumulation of rotting biomass in the deeper portions of the lake and the onset of deep water hypoxia. From a resiliencebased management perspective, the frontloop presents a framework that urges anticipatory management focus on events that undermine system resilience during the conservation phase.

The insight to be gained from the frontloop is that research and management effort should focus on identification and long-term monitoring of plausible factors or attributes that could undermine resilience of the conservation phase and accelerate transition to the release phase. Attention must be paid to selecting a suite of indicators that are correlated with the functional status of one or several vital 
ecosystem processes and properties. Monitoring diatom assemblages, water quality, including dissolved oxygen in the lake, its tributaries, and associated wetlands is critical for early detection and management of nutrient enrichment. Stock assessments could also yield crucial insights into the food-web structure of the fisheries.

\section{Release and reorganization phase: backloop}

The release, i.e., collapse, of the haplochromine cichlids of Lake Victoria is linked to the irruption of the Nile perch and can be illustrated as follows:

1. Increased deforestation, cultivation, urban effluence, and influx of nutrients into Lake Victoria owing to rapid human population growth that in turn precipitated large algal blooms that increased eutrophication and exacerbated deep water anoxia;

2. Introduction of the fecund, voracious Nile perch into Lake Victoria in the 1950s and 1960s to promote commercial fishery;

3. Intense predation pressure on the haplochromine cichlids accelerated a phytoplankton boom and eutrophication, thus reducing light penetration and increasing deep water anoxia, contributing further to the decline of the haplochromine cichlids;

4. Nile perch composed more than $80 \%$ of the catch. The remaining $20 \%$ consisted of Nile tilapia, the tiny native omena (Rastrineobola argentea), and a small remnant of other native fishes.

Conversely, the resurgence, i.e., renewal, of the haplochromine cichlids is linked with the recent decline of the Nile perch fisheries in Lake Victoria owing largely to intense fishing efforts linked to global markets. The recovery of the haplochromine cichlids can be characterized as follows:

1. Intensive fishing pressure on the Nile perch over the last two decade (Balirwa et al. 2003);

2. The functional response of the haplochromine cichlids to high turbidity, deep water anoxia, and dietary shift to larger prey (Witte et al. 2000, Katunzi et al. 2003) has enabled recovery of haplochromine cichlids;
3. The existence of habitat structural diversity owing to papyrus dominated wetlands and rock outcrops provided barriers and refugia from Nile perch, thus serving as ecological fallows or legacies providing propagule for haplochromine resurgence;

4. Nile perch biomass declined to $76 \%$ while that of haplochromine cichlids increased to $21 \%$ (Witte et al. 2000).

The resurging haplochromine cichlid populations are encountering a lake with dramatically transformed habitat conditions. The recovering haplochromine cichlids have to cope with: (1) high turbidity, hence low water transparency; (2) deep water hypoxia; and (3) changes in food composition. Witte et al. (2000) have suggested that differences in phenotypic plasticity of anatomical, ecological, or life history traits may have been crucial in determining recovery or survival of the haplochromine cichlids in limnological conditions that are dramatically different from the conditions prior to the irruption of the Nile perch. For instance, low haplochromine densities and eutrophication have relaxed mate selectivity in females leading to interspecific hybridization (Seehausen et al. 1997). Similarly, gill morphology and body size of some resurging haplochromines have a surface area considerably larger than the pre-Nile perch specimen. This is likely to be in response to or an adaptation to hypoxia (Kaufman 1992, Chapman et al. 2003).

In the context of Lake Victoria and using the adaptive renewal cycle framework, some specific but generalizable propositions are offered on potential management actions to nurture renewal and delay the onset of release or collapse.

\section{Management actions that nurture renewal: backloop}

Managing actions that nurture renewal include the need to identify and reduce anthropogenic nutrient inputs through reforestation of upland catchment areas as well as reduce materials and contaminants in surface run-off; apply appropriate levels of fishing effort on selected Nile perch size classes and other target species to enhance recovery of haplochromine biodiversity; and maintain structural diversity by the protection of critical habitats such as wetlands and rocky island habitats, which serve as refugia and sites for recruitment. 
Wetlands and rocky island habitats have provided valuable structural diversity and served as refugia for haplochromine fishes (Chapman et al. 2003, Chapman and Chapman 1996). Wetlands and rocky islands could be explored for the feasibility of establishing fish "parks" or "reserves" for special protection because of high abundance of haplochromine cichlids. Balirwa et al. (2003) have suggested that ecotonal wetlands have been especially critical refugia because interactions with the main lake elevate dissolved oxygen, making these habitats both favorable and safe for haplochromine cichlids.

\section{Management actions that delay release: frontloop}

Managing actions to reduce release include the need to implement landscape level management, including wetlands, forests, and lowland urban areas to reduce eutrophication from nutrient run-off and urban effluence; develop an ecosystems model of Lake Victoria that includes the physical, chemical, biological, and anthropogenic factors to understand and predict changes in primary productivity; and quantify interactions among food-web structures, water quality, and life-history characteristics of fishes to understand the relationship between productivity of haplochromine cichlids, Nile perch predation, and the causes of eutrophication in Lake Victoria.

\section{CONCLUSION}

The resilience of the haplochromine cichlid fisheries appears to be determined by the genetic diversity, functional and response diversity, and ecosystem diversity (beta diversity) across the range of habitats in Lake Victoria. The wetlands and rocky habitats provide the capacity for renewal and recovery of haplochromine cichlids. These areas contain the ecological memory that is critical to the ecological resilience of Lake Victoria and avoiding irreversible shifts between the Nile perch dominated regime and the haplochromine cichlid regime. Moreover, wetlands and rocky habitats are a source of "external" memory that provides source areas and propagules for colonization from outside the highly disturbed main lake.

The adaptive renewal cycle provides an intuitive conceptual and management framework upon which to explore resilience-based ecosystem management for Lake Victoria. Rapid evolutionary radiation, low levels of predation, low fishing effort, and high primary productivity were critical in the growth and conservation, i.e., frontloop, phase of the haplochromine cichlid dominated regime. The abundance of the haplochromine cichlids may have provided sufficient grazing pressure on the phytoplankton, controlled eutrophication, and thus maintained high concentrations of deep water oxygen as well as sufficient illumination, hence conferring resilience to the conservation phase.

However, intense predation on the haplochromine cichlids following the Nile perch irruption released grazing pressure on the phytoplankton and accelerated eutrophication, thus exacerbating haplochromine cichlid extirpation and Nile perch domination of Lake Victoria fisheries. This paper proposes resilience-based actions to nurture the renewal phase. These include slowing down eutrophication through sustainable land management, targeting selected harvesting of the Nile perch to enhance recovery of the haplochromine, and maintaining structural diversity by protecting wetlands, satellite lakes, and rocky island habitats that serve as ecological memory and spatial resilience.

Responses to this article can be read online at:

http://www.ecologyandsociety.org/vol16/iss 1/art9/responses/

\section{Acknowledgments:}

Special thanks to Mercy Ojwang and Ronald Ndesanjo for research support.

\section{LITERATURE CITED}

Adger, W. N., T. P Hughes, C. Folke, S. R. Carpenter, and J. Rockstrom. 2005. Socialecological resilience to coastal disasters. Science 309:1036-1039.

Balirwa, J. S., C. A. Chapman, L. J. chapman, K. Geheb, R. Lowe-McConnell, O. Seehausen, J. Wanink, R. Welcomme, and F. Witte. 2003. Biodiversity and fishery sustainability in the Lake Victoria Basin: an unexpected marriage? Bioscience 53:703-715. 
Bruton, M. N. 1990. The conservation of the fishes of Lake Victoria, Africa: an ecological perspective. Environmental Biology of Fishes 27:161-175.

Budeba, Y. L., and I. G. Cowx. 2007. The role of freshwater shrimp Caridina nilotica (Roux) in the diet of major commercial fish species in Lake Victoria, Tanzania. Aquatic Ecosystem Health and Management 10(4):368-380.

Carpenter, S. R., and W. A. Brock. 2006. Rising variance: a leading indicator of ecological transition. Ecology Letters 9(3):311-318.

Chapman, L. J., and C. A. Chapman. 1996. Wetland ecotones as refugia for endangered fishes. Biological Conservation 78:263-270.

Chapman, L. J., C. A. Chapman, P. J. Schofield, J. P. Olowo, L. Kaufman, O. Seehausen, and R. OgutuOhwayo. 2003. Faunal resurgence in Lake Navugabo, East Africa. Conservation Biology 17 (2):500-511.

Chapman, L. J., L. S. Kaufman, C. A. Chapman, F. E. Mckenzie. 1995. Hypoxia tolerance in 12 species of East African cichlids-potential for low-oxygen refugia in Lake Victoria. Conservation Biology 9 (5):1274-1288.

Crutzen, P. 2002. The anthropocene: geology of mankind. Nature 415:23.

Elmqvist, T., C. Folke, M. Nystrom, G. Peterson, J. Bengtsson, B. Walker, and J. Norberg. 2003. Response diversity, ecosystem change, and resilience. Frontiers of Ecology and Environment 1 (9):488-494.

Folke, C. 2006. Resilience: the emergence of a perspective for social-ecological systems analyses. Global Environmental Change 16:253-267.

Folke, C., S. Carpenter, B. Walker, M. Scheffer, T. Elmqvist, L. Gunderson, and C. S. Holling. 2004. Regime shifts, resilience and biodiversity in ecosystem management. Annual Review of Ecology, Evolution, and Systematics 35:557-581.

Franklin, J. F., and J. A. MacMahon. 2000. Enhanced: messages from a mountain. Science 288:1183-1184.
Goldschmidt, T., F. Witte, and J. H. Wanink. 1993. Cascading effects of the introduced Nile perch on the detritivorous/phytoplanktivorous species in the sublittoral areas of Lake Victoria. Conservation Biology 7:686-700.

Gunderson, L. H. 2000. Ecological resilience-in theory and application. Annual Review of Ecological Systems 31:425-439.

Hecky, R. E., F. W. B. Bugenyi, P. Ochumba, J. F. Talling, R. Mugidde, M. Gophen, and L. S. Kaufman. 1994. Deoxygenation of the deep water of Lake Victoria, East Africa. Limnology and Oceanography 39:1476-1481.

Holling, C. S. 1973. Resilience and stability of ecological systems. Annual Review of Ecological Systems 4:1-23.

Holling, C. S. 1986. The resilience of terrestrial ecosystems: local surprise and global change. Pages 292-317 in W. C. Clark and R. E. Munn, editors. Sustainable development of the biosphere. Cambridge University Press, Cambridge, UK.

Holling, C. S., and L. H. Gunderson. 2002. Resilience and adaptive cycles. Pages 25-62 in L. H. Gunderson and C. S. Holling, editors. Panarchy: understanding transformations in human and natural systems. Island Press, Washington, D.C., USA.

Holling, C. S., and G. K. Meffe. 1996. Command and control and the pathology of natural resource management. Conservation Biology 10:328-327.

Katunzi, E. F. B., J. Zoutendijk, T. Goldschmidt, J. Wanink, and F. Witte. 2003. Lost zooplanktivorous cichlids from Lake Victoria reappear with a new trade. Ecology of Freshwater Fish 12:237-240.

Kaufman, L. S. 1992. Catastrophic change in species-rich freshwater ecosystems: the lessons of Lake Victoria. Bioscience 42(11):846-858.

Lundberg, J., and F. Moberg. 2003. Mobile link organisms and ecosystem functioning: implications for ecosystem resilience and management. Ecosystems 6:87-98. 
Millennium Ecosystem Assessment (MA). 2005. Ecosystems and human well-being: current state and trends. Island Press, Washington, D.C., USA.

Nystrom, M., C. Folke, and F. Moberg. 2000. Coral reef disturbance and resilience in a humandominated environment. Trends in Ecology and Evolution 15:413-417.

Ogutu-Ohwayo, R. 1990. The decline in the native fishes of Lake Victoria and Kyoga (East Africa) and the impact of the introduced species, especially the Nile perch, Lates niloticus and Nile tilapia Oreochromis niloticus. Environmental Biology of Fishes 27:81-96

Peterson, G. D., C. R. Allen, and C. S. Holling. 1998. Ecological resilience, biodiversity and scale. Ecosystems 1:6-18.

Pharo, E. J., and D. B. Lindenmeyer. 2009. Biological legacies soften pine plantation effects for bryophytes. Biodiversity and Conservation 18 (7):1751-1764.

Scheffer, M., and S. R. Carpenter. 2003. Catastrophic shifts in ecosystems: linking theory to observation. Trends in Ecology and Evolution 18:648-656.

Scheffer, M., S. R. Carpenter, J. Foley, C. Folke, and B. H. Walker. 2001. Catastrophic shifts in ecosystems. Nature 413:591-596.

Seehausen, O. J., M. van Alphen, and F. Witte. 1997. Cichlid fish diversity threatened by eutrophication that curbs sexual selection. Science. 277:1808-1811.

Verschuren, D., T. C. Johnson, H. J. Kling, and D. N. Leavitt. 2002. The chronology of human impact on Lake Victoria, East Africa. Proceedings of Royal Society London 269:289-294.

Walker, B. H. 1992. Biodiversity and ecological redundancy. Conservation Biology 6:18-23.

Walker, B. H, C. S. Holling, S. C. Carpenter, and A. P. Kinzig. 2004. Resilience, adaptability and transformability in social-ecological systems. Ecology and Society 9(2): 5. [online] URL: http://w ww.ecologyandsociety.org/vol9/iss2/art5/.

Wanink, J. H. 1991. Survival in a perturbed environment: the effects of Nile perch introduction on the zooplanktivorous fish community of Lake Victoria. Pages 269-275 in O. Ravera, editor. Terrestrial and aquatic ecosystems: perturbation and recovery. Ellis Horwood, Chichester, New York, USA.

Witte, F., T. Goldschmidt, J. H. Wanink, M. J. P. van Oijen, P. C. Goudswaard, E. L. M. Witte-Maas, and N. Bouton. 1992. The destruction of an endemic species flock: quantitative data on the decline of the haplochromine species from the Mwanza Gulf of Lake Victoria. Environmental Biology of Fishes 34:1-28.

Witte, F., B. S. Msuku, J. H. Wanink, O. Seehausen, E. F. B. Katunzi, P. C. Goudswaard, and T. Goldschmidt. 2000. Recovery of cichlid species in Lake Victoria: and examination of factors leading to differential extinction. Reviews in Fish Biology and Fisheries 10:233-241.

World Commission on Environment and Development (WCED). 1987. Our common future. Oxford University Press, New York, NY, USA. 